\title{
PHOTOAFFINITY LABELING OF BENZODIAZEPINE RECEPTORS CAUSES ALTERED AGONIST-ANTAGONIST INTERACTIONS
}

\author{
JOHN W. THOMAS AND JOHN F. TALLMAN
}

Section on Molecular Pharmacology, Neuroscience Branch, National Institute of Mental Health, Bethesda, Maryland 20205

Received July 8, 1982; Revised September 7, 1982; Accepted September 10, 1982

\begin{abstract}
Previous studies have shown that $\left[{ }^{3} \mathrm{H}\right]$ flunitrazepam forms irreversible cross-links with brain tissue when exposed to ultraviolet irradiation. Comparison of the amount of $\left[{ }^{3} \mathrm{H}\right]$ flunitrazepam irreversibly incorporated and the number of benzodiazepine binding sites blocked after photolabeling has indicated that several binding sites are inactivated for each molecule of $\left[{ }^{3} \mathrm{H}\right]$ flunitrazepam incorporated. To learn the cause of this discrepancy, binding to the benzodiazepine binding sites has been examined using several radiolabeled benzodiazepine antagonists. Binding of a $\beta$-carboline ester, CGS-8216, and Ro 15-1788 was not altered by photolabeling; however, displacement studies revealed that photolabeling converted a homogeneous set of benzodiazepine binding sites into two subsets: one of high affinity (unaltered sites) and one of low affinity. The low affinity sites could be detected by displacement studies of antagonist binding by benzodiazepines, and conversion to a low affinity form accounts for the discrepancy observed after photolabeling using $\left[{ }^{3} \mathrm{H}\right]$ flunitrazepam as ligand.
\end{abstract}

High affinity benzodiazepine binding sites have been described in brain, and intensive study of their properties has led to the hypothesis that the major actions of the benzodiazepines may be mediated through interactions with GABA-ergic neuronal mechanisms (Costa and Guidotti, 1979; Tallman et al., 1980; Haefely et al., 1981). These interactions seem to be allosteric between one of the GABA receptors (Browner et al., 1981) and the high affinity binding site for the benzodiazepines (Tallman et al., 1978; Massotti et al., 1981). A third component of this system is a site closely related to a channel for anions; it has been studied by examining the binding of picrotoxinin (Leeb-Lundberg and Olsen, 1980) and seems to be the site of action of several other compounds capable of interacting with the benzodiazepines (Williams and Risley, 1979).

Previously, we (Yousufi et al., 1979) and others (Gavish et al., 1979; Lang et al., 1979) have solubilized the benzodiazepine binding site from brain; in the course of these studies, the ability to photolabel this binding site (Möhler et al., 1980) was exploited to study the properties of the active binding site. When membrane preparations were studied, several siles were inactivated for each site labeled (Möhler et al., 1980; Thomas and Tallman, 1981); in soluble preparations, as many sites were inactivated as labeled (Thomas and Tallman, 1981). Among the possible explanations for these data, conversion of the

\footnotetext{
${ }^{1}$ To whom correspondence should be addressed at NIMH, Building 10, Room 3N256, 9000 Rockville Pike, Bethesda, MD 20205.
}

high affinity binding sites for the benzodiazepines to a low affinity form was discussed (Thomas and Tallman, 1981).

To examine this possibility, binding to the benzodiazepine site was carried out with the radiolabeled antagonists ethyl- $\beta$-carboline-3-carboxylate (Nielsen et al., 1981; Braestrup and Nielson, 1981), CGS 8216 (Czernik et al., 1982), and Ro 15-1788 (Hunkeler et al., 1981; Möhler and Richards, 1981). Binding of these antagonists was not altered by photolabeling; however, the ability of benzodiazepines to displace antagonist binding was altered with competition curves shifted to the right. These results are consistent with photolabeling converting a homogeneous set of benzodiazepine binding sites into two subsites of high and low affinity.

\section{Materials and Methods}

Reagents were purchased or prepared essentially as previously described (Thomas and Tallman, 1981), with the following additions. $\left[{ }^{3} \mathrm{H}\right]$ Ethyl- $\beta$-carboline-3-carboxylate (Lot No. 15-182, Sp. Act. $80.6 \mathrm{Ci} / \mathrm{mmol}$ ) was obtained from New England Nuclear. The nonspecific binding obtained with this lot of ligand was less than $15 \%$ of the total binding for a ligand concentration of $1 \mathrm{nM} .\left[{ }^{3} \mathrm{H}\right]$ $\beta$-Carboline solutions were prepared fresh daily from the ethanol stock solution due to concern for the stability of this compound's ester linkage. $\left[{ }^{3} \mathrm{H}\right]$ Ro $15-1788$ (Lot. No. 1538-145, Sp. Act. $87.5 \mathrm{Ci} / \mathrm{mmol}$ ) was obtained from New England Nuclear. The nonspecific binding obtained with this lot of ligand was less than $5 \%$ of the total binding for 
a ligand concentration of $1 \mathrm{nM} .\left[{ }^{3} \mathrm{H}\right.$ ]CGS $8216(20.1 \mathrm{Ci} /$ mmol), CGS 8216, and CSG 9896 were generous gifts from Drs. William Cash and Barbara Petrack of CIBAGEIGY Corp. (Pharmaceutical Division, Summit, NJ). The structural formula for CGS 8216 is given by Czernik et al. (1982); CGS 9896 is the 4-chlorophenyl analog of CGS 8216. The nonspecific binding obtained with $\left[{ }^{3} \mathrm{H}\right]$ CGS 8216 was less than $10 \%$ of the total binding for a ligand concentration of $\left.0.1 \mathrm{nM} .{ }^{3} \mathrm{H}\right]$ Flunitrazepam (Lot. No. 1538-111, Sp. Act. $87.3 \mathrm{Ci} / \mathrm{mmol}$ ) was obtained from New England Nuclear. The nonspecific binding obtained with this lot of ligand was less than $10 \%$ of the total binding for a ligand concentration of $1 \mathrm{nM}$. Other unlabeled drugs were kindly provided by Dr. William Scott at Hoffmann-LaRoche (Nutley, NJ).

Preparation and photolabeling of forebrain homogenates. Tissue homogenates were prepared and photolabeled as described previously (Thomas and Tallman, 1981). Forebrain tissue containing cortical, hippocampal, and striatal brain regions (Glowinski and Iversen, 1966) was used in all studies. Control membranes were prepared in a manner which was identical to the photolabeled membranes (exposed to ultraviolet light, $\left[{ }^{3} \mathrm{H}\right]$ flunitrazepam, and washing) except for the inclusion of $10^{5}$ M lorazepam, which blocks photolabeling. Untreated membranes were not subjected to ultraviolet light or extensive washing. Since earlier unpublished results had shown no alteration in binding to homogenates that had been frozen, tissue homogenates were routinely prepared in large batches and frozen in aliquots, so that both displacement studies and Scatchard analyses could be performed on identical forebrain tissue preparations. The findings reported here have been observed in three or more separate tissue preparations.

Binding assays were performed as previously described (Tallman et al., 1978), with the following minor modifications. Samples were incubated for $1 \mathrm{hr}$, and incubations were terminated quickly by adding $6.5 \mathrm{ml}$ of ice-cold Tris- $\mathrm{HCl}\left(\mathrm{pH} 7.5\right.$ at $\left.5^{\circ} \mathrm{C}\right)$ to the incubation mixture. The diluted incubation mixture was immediately filtered, and the filter was washed twice with $6.5 \mathrm{ml}$ of ice-cold Tris$\mathrm{HCl}$. For $\left[{ }^{3} \mathrm{H}\right]$ flunitrazepam binding assays, nonspecific binding was determined by including $10 \mu \mathrm{M}$ diazepam. For $\left[{ }^{3} \mathrm{H}\right]$ ethyl- $\beta$-carboline-3-carboxylate, $\left[{ }^{3} \mathrm{H}\right]$ CGS 8216 , and $\left.{ }^{3} \mathrm{H}\right]$ Ro $15-1788$ assays, nonspecific binding was determined by including $1 \mathrm{~mm}$ lorazepam. This high level of lorazepam was necessary due to a set of low affinity benzodiazepine binding sites which appeared after photolabeling (see "Results"). Binding assays for $\left[{ }^{3} \mathrm{H}\right]$ flunitrazepam, $\left[{ }^{3} \mathrm{H}\right]$ ethyl- $\beta$-carboline-3-carboxylate, and $\left[{ }^{3} \mathrm{H}\right]$ Ro 15-1788 were done in a final incubation volume of 0.5 $\mathrm{ml}$ and contained 300 to $400 \mu \mathrm{g}$ of protein. Binding assays for $\left.{ }^{3} \mathrm{H}\right] \mathrm{CGS} 8216$ were done in a final incubation volume of $1.0 \mathrm{ml}$ and contained 150 to $200 \mu \mathrm{g}$ of protein.

\section{Results}

As we have previously indicated (Thomas and Tallman, 1981), photolabeling of benzodiazepine binding sites in the membrane with flunitrazepam results in the inactivation of more sites than the number of sites labeled (Fig. 1A; Table I). Inhibition is noncompetitive in nature.
In contrast, following photolabeling with flunitrazepam, no alteration was observed in the number of binding sites for $\left[{ }^{3} \mathrm{H}\right]$ ethyl- $\beta$-carboline-3-carboxylate, $\left[{ }^{3} \mathrm{H}\right] \mathrm{CGS}-8216$, or $\left[{ }^{3} \mathrm{H}\right]$ Ro $15-1788$ (Fig. $1 B, C$, and $D$; Table I). Conditions chosen in the experiment resulted in specific labeling of one-quarter of the sites, so that a theoretical decrease of about $25 \%$ might be expected for the binding of benzodiazepines and benzodiazepine antagonists. However, no significant changes were noted for the number of ethyl- $\beta$-carboline-3-carboxylate, CGS 8216, and Ro $15-1788$ sites, whereas approximately one-half of the $\left[{ }^{3} \mathrm{H}\right]$ flunitrazepam binding sites were no longer present after photolabeling. On the other hand, each benzodiazepine antagonist is capable of inhibiting photolabeling with flunitrazepam (data not shown).

To resolve this paradox, the ability of a series of benzodiazepines to displace $\left[{ }^{3} \mathrm{H}\right]$ ethyl- $\beta$-carboline-3-carboxylate binding was investigated. As previously published (Nielsen et al., 1981; Braestrup and Nielsen, 1981), the benzodiazepines are capable of displacing $\left[{ }^{3} \mathrm{H}\right]$ ethyl$\beta$-carboline binding from untreated brain membranes (Fig. 2). In general, displacement is monophasic in forebrain and consistent with the interpretation that the compounds interact with the same site. Following photolabeling in the presence of flunitrazepam, the displacement curve is shifted to the right and flattened consistent with the interpretation that the compounds interact with more than one set of binding sites (Fig. 2). In control membranes in which photolabeling was mostly blocked with lorazepam, but exposed to ultraviolet light in the presence of flunitrazepam, only a slight shift was noted (Fig. 2). In addition, no shift in the displacement curve was observed in membranes exposed to ultraviolet light in the absence of flunitrazepam or exposed to ultraviolet light in the presence of lorazepam (data not shown).

A similar right shift and flattening of the displacement curves for several other benzodiazepines was noted (Table II), indicating a consistent change in the benzodiazepine site with photolabeling. In contrast, as expected from the saturation data shown (Fig. 1), only slight differences were noted in the ability of various antagonists to displace bound $\left[{ }^{3} \mathrm{H}\right]$ ethyl $-\beta$-carboline-3-carboxylate. Compounds tested include ethyl- $\beta$-carboline-3-carboxylate and two analogs, CGS 8216 and its 4-fluorophenyl analog, CGS 9896, and Ro 15-1788 (Table II; Fig. $3)$.

The Hill coefficients for the inhibition of $\left[{ }^{3} \mathrm{H}\right]$ ethyl $-\beta$ carboline-3-carboxylate binding by benzodiazepines reflect the changes seen in the displacement curves (Table II). The coefficients for benzodiazepines inhibiting binding to photolabeling membranes range from 0.50 to 0.63 , whereas in control membranes the values are near unity (range: 0.83 to 0.95 ). In contrast, the Hill coefficients for the inhibition of $\beta$-carboline binding by various antagonists were similar and near unity in both control and photolabeled membranes. Hill coefficients in the forebrain less than one were obtained for CL 218,872, in agreement with earlier published data (Lippa et al., 1979); they were not altered by photolabeling. In an identical preparation from cerebellum, Hill coefficients near unity were observed for both control and photolabeled mem- 


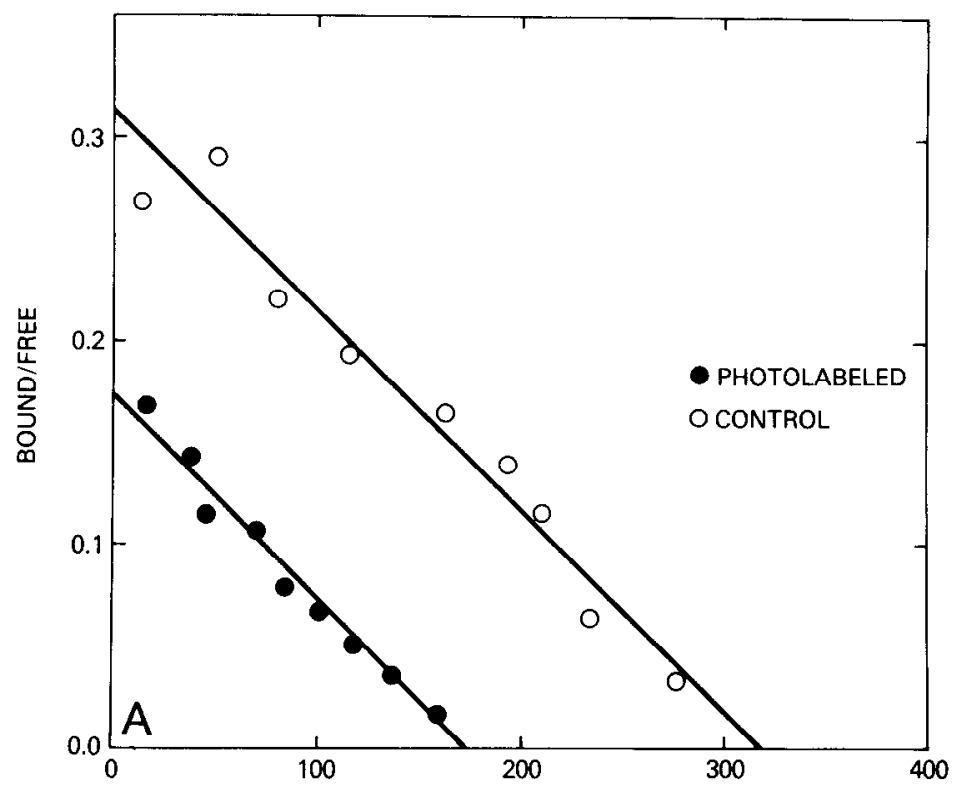

[3H] FLUNITRAZEPAM BOUND (fmol)

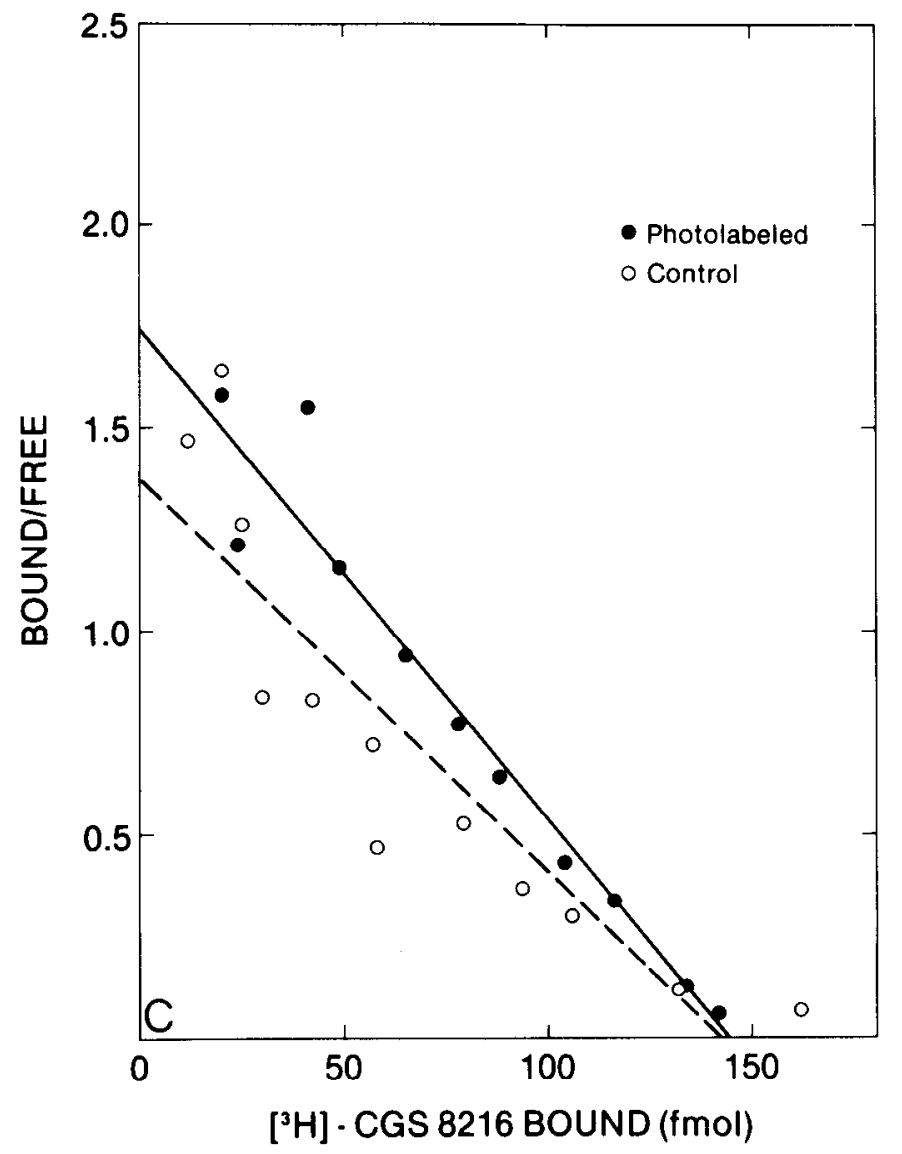

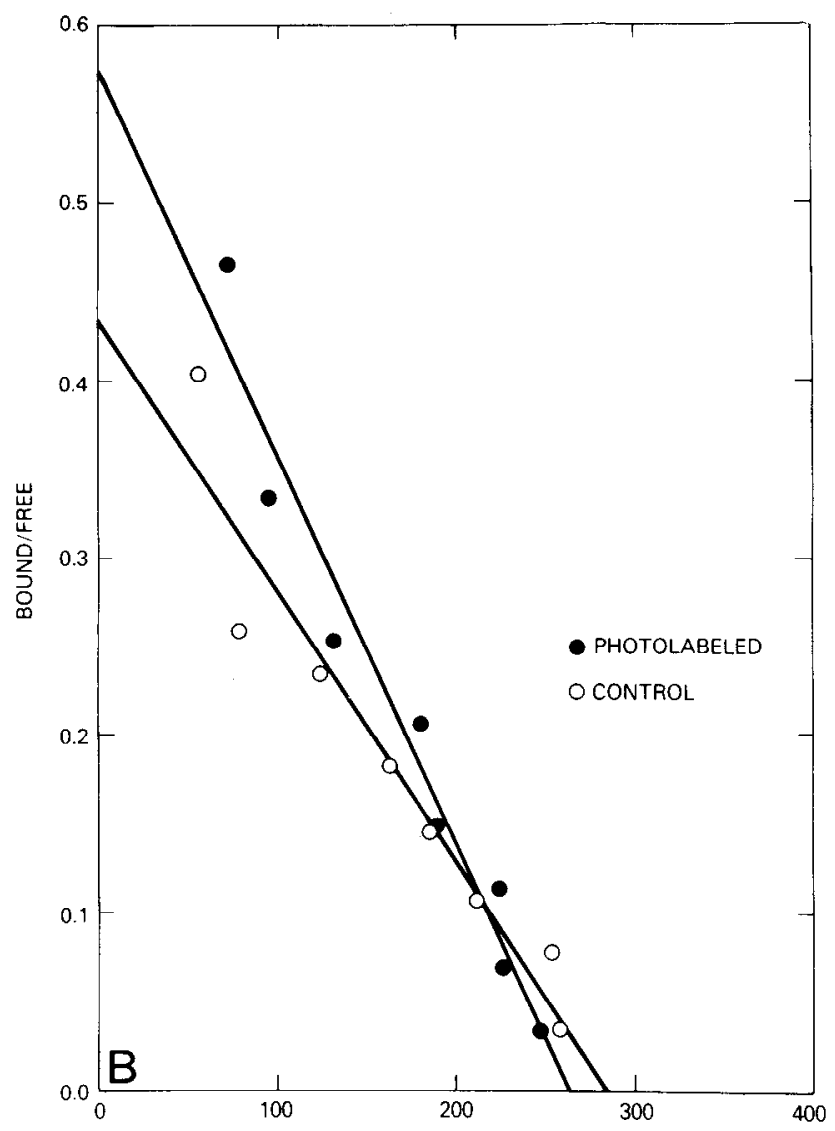

[3H]-ETHYL $\beta$-CARBOLINE-3-CARBOXYLATE BOUND (fmol)

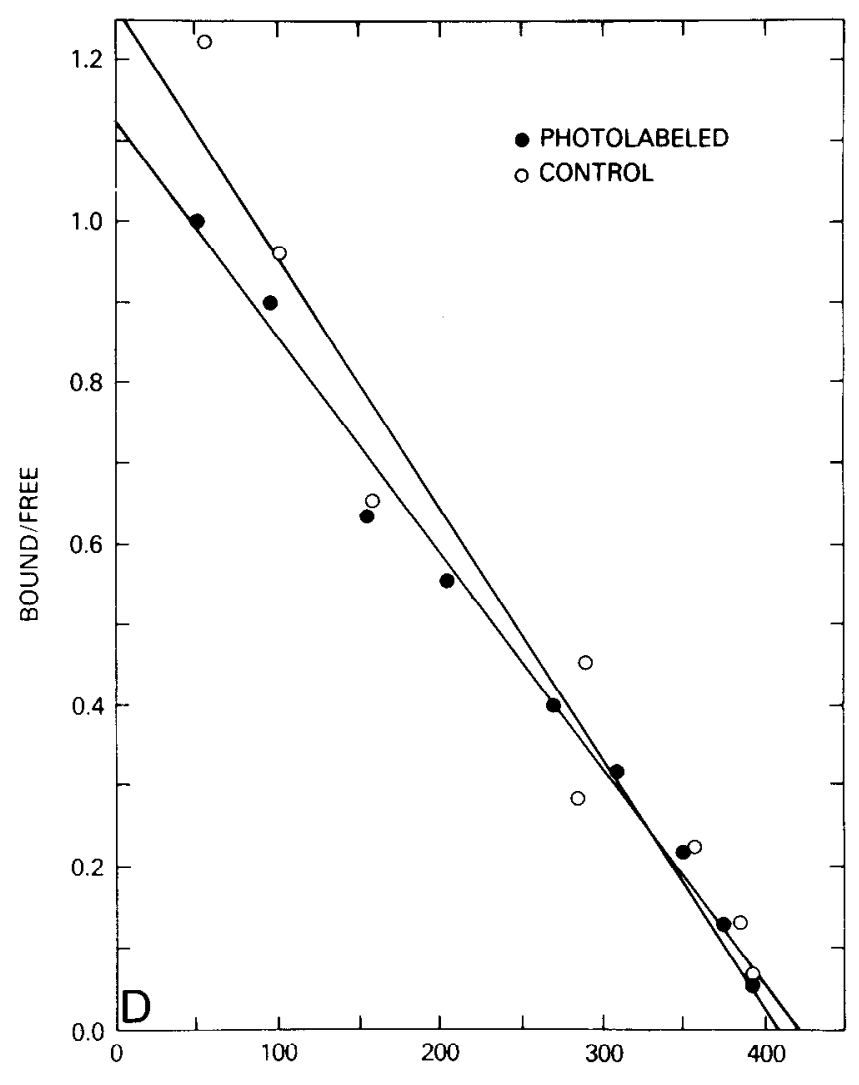

${ }^{3} \mathrm{H}$-Ro 15-1788 BOUND (fmol)

Figure 1. A, Scatchard analysis of $\left[{ }^{3} \mathrm{H}\right]$ flunitrazepam binding to control and photolabeled forebrain tissue. The ligand concentration ranged from $0.2 \mathrm{~nm}$ to $20 \mathrm{nM}$. B. Scatchard analysis of $\left[{ }^{3} \mathrm{H}\right] \beta$-carboline binding to control and photolabeled forebrain tissue. The ligand concentrations ranged from $0.2 \mathrm{nM}$ to $20 \mathrm{nM}$. $C$, Scatchard analysis of $\left[{ }^{3} \mathrm{H}\right] \mathrm{CGS} 8216$ binding to control and photolabeled forebrain tissue. The ligand concentration ranged from $0.025 \mathrm{nM}$ to $2.5 \mathrm{nM}$. $D$, Scatchard analysis of [ $\left.{ }^{3} \mathrm{H}\right] \mathrm{Ro}$ 15-1788 binding to control and photolabeled forebrain tissue. The ligand concentration ranged from $0.2 \mathrm{~nm}$ to $20 \mathrm{nM}$. 
TABLE I

Comparison of the number of membrane-bound sites labeled and inactivated by flunitrazepam photolabeling

Forebrain tissue was photolabeled by ultraviolet irradiation in the presence of $5 \mathrm{~nm}$ flunitrazepam. In control incubations, photolabeling was blocked by including $10^{-5} \mathrm{M}$ lorazepam. After irradiation, the particulate membrane fraction was washed repeatedly to remove reversibly bound material. The washed membrane pellets were stored frozen at $-20^{\circ} \mathrm{C}$ until they were assayed for $\left[{ }^{3} \mathrm{H}\right]$ flunitrazepam or $\left[{ }^{3} \mathrm{H}\right] \beta$-carboline binding. Values are means \pm SEM.

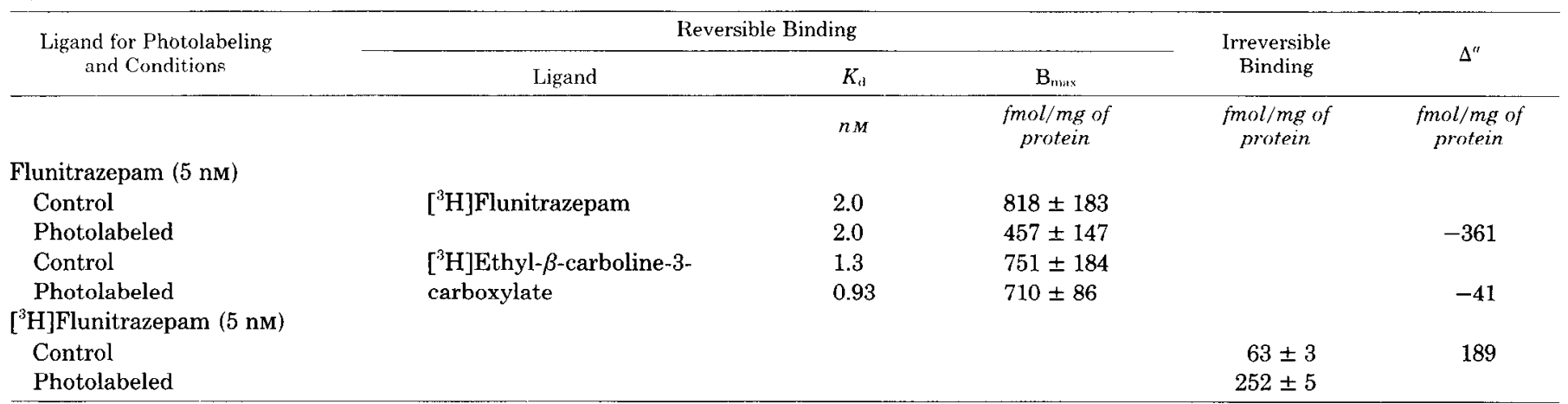

" $\Delta=$ Photolabeled value (fmol/mg of protein) - Control value (fmol/mg of protein).

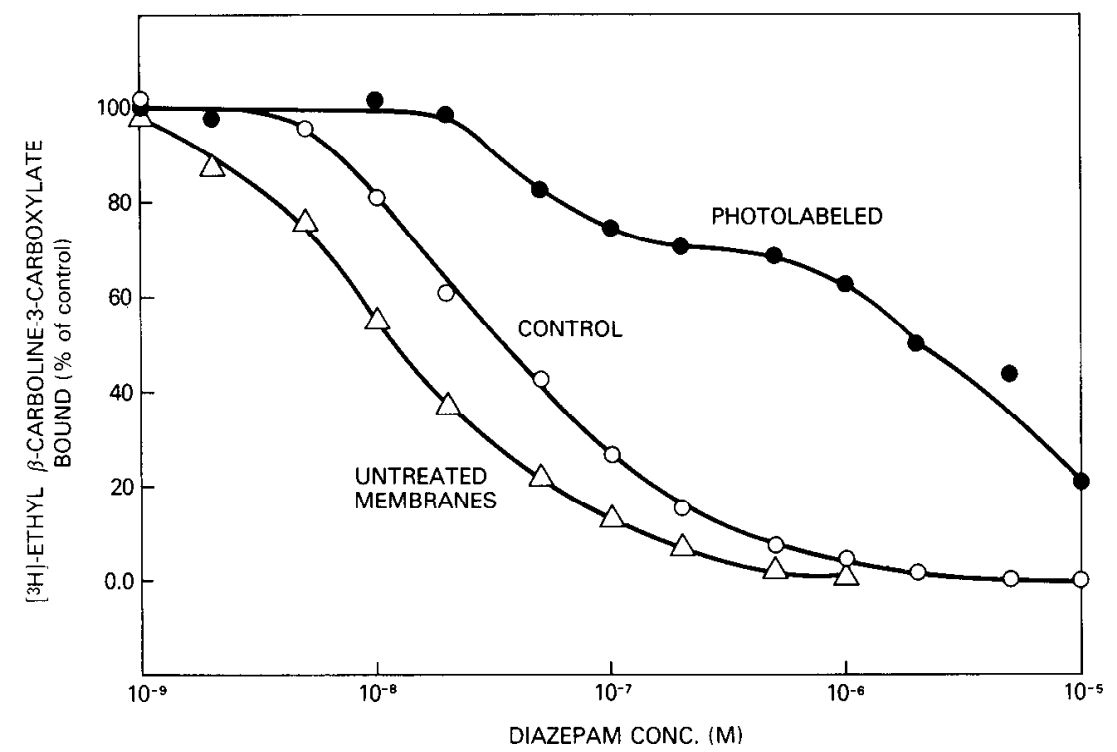

Figure 2. Diazepam displacement curves of $\left[{ }^{3} \mathrm{H}\right] \beta$-carboline bound to untreated, control, or photolabeled forebrain tissue. Control membranes were prepared in a manner which was identical to the photolabeled membranes except for the inclusion of $10^{-5} \mathrm{M}$ lorazepam, which blocks photolabeling. The ligand concentration was $1 \mathrm{nM}$.

branes (photolabeled membranes: $\mathrm{IC}_{50}=460 \mathrm{nM}, n_{\mathrm{H}}=$ 1.1; control membranes: $\mathrm{IC}_{50}=150 \mathrm{nM}, n_{\mathrm{H}}=0.98$ ). The ability of CL 218,872 to interact with the binding site is different from the benzodiazepines in two separate areas where it shows different displacement from untreated membranes.

To determine if the shifts seen in the competition curves for benzodiazepine inhibition of $\beta$-carboline binding could be demonstrated with other radiolabeled antagonists, the binding of $\left[{ }^{3} \mathrm{H}\right] \mathrm{CGS} 8216$ was also investigated. The displacement data obtained are in agreement with those obtained for $\beta$-carboline binding (Fig. 1; Table III). The displacement curves for benzodiazepine inhibition of $\left[{ }^{3} \mathrm{H}\right] \mathrm{CGS}-8216$ binding are shifted to the right and flattened for photolabeled membranes as compared to control membranes (Table III; Fig. 4). In contrast, inhibition of $\left[{ }^{3} \mathrm{H}\right]$ CGS 8216 binding by Ro $15-1788$, CGS 8216 , CGS 7896 , and ethyl- $\beta$-carboline-3-carboxylate is unaffected by photolabeling with flunitrazepam.
The saturation data and competition experiments both suggested a relationship between photolabeling and the disappearance of high affinity benzodiazepine binding sites. To examine this relationship, the time course of the photolabeling reaction was investigated (Fig. 5). Both $\left[{ }^{3} \mathrm{H}\right] \beta$-carboline binding and $\left[{ }^{3} \mathrm{H}\right]$ flunitrazepam binding were determined for samples photolabeled for various lengths of time up to $20 \mathrm{~min}$. Total $\beta$-carboline binding increased with time consistent with the slight increase in $K_{\mathrm{d}}$ caused by photolabeling (Fig. $1 B$ ). Initially an intermediate concentration of diazepam inhibited more than $50 \%$ of the total $\beta$-carboline binding, but the amount of inhibition decreased with time and was less than $10 \%$ for membrane samples photolabeled for $10 \mathrm{~min}$. A similar time course was observed for the disappearance of $\left[{ }^{3} \mathrm{H}\right]$ flunitrazepam binding, and approximately a $90 \%$ decline in specific $\left[{ }^{3} \mathrm{H}\right]$ flunitrazepam binding was observed in membranes photolabeled for $10 \mathrm{~min}$. At this time about $25 \%$ of the benzodiazepine binding sites are photolabeled 
by $\left[{ }^{3} \mathrm{H}\right]$ flunitrazepam. Nonspecific binding of both $\left[{ }^{3} \mathrm{H}\right]-$ $\beta$-carboline and $\left[{ }^{3} \mathrm{H}\right]$ flunitrazepam did not change with time.

\section{Discussion}

The results of this study clearly indicate the progressive conversion (Fig. 5) of a high affinity binding site for the benzodiazepines into a much lower affinity state by photolabeling. Since most receptor binding studies, for

\section{TABLE II}

$I C_{50}$ for inhibition of $l^{3} \mathrm{H}$ Jethyl- $\beta$-carboline-3-carboxylate binding

Control and photolabeled forebrain tissue was prepared as described in Table I (also see "Materials and Methods"). Displacement curves for each inhibitor were determined as shown in Figure 2 for diazepam and in Figure 3 for Ro 15-1788. The ligand concentration was $1 \mathrm{nM}$. Hill plots were constructed from inhibition curves by plotting $\log [\mathbf{P} /(100$ $P)]$ versus $\log I$ where $P$ is the percent bound and $I$ is the inhibitor concentration (Bylund, 1980). The Hill coefficient, $n_{\mathrm{H}}$, was determined by linear regression analysis.

\begin{tabular}{|c|c|c|c|c|c|}
\hline \multirow{3}{*}{ Inhibitor } & \multicolumn{4}{|c|}{$\mathrm{IC}_{50}$} & \multirow{3}{*}{ Ratio $^{a}$} \\
\hline & \multicolumn{2}{|c|}{$\begin{array}{l}\text { Photolabeled } \\
\text { Membranes }\end{array}$} & \multicolumn{2}{|c|}{$\begin{array}{c}\text { Control } \\
\text { Membranes }\end{array}$} & \\
\hline & $\mathrm{nM}$ & $n_{\mathrm{H}}$ & nм & $n_{\mathrm{H}}$ & \\
\hline Clonazepam & 30 & 0.50 & 3 & 0.92 & 10 \\
\hline Flunitrazepam & 400 & 0.51 & 12 & 0.87 & 33 \\
\hline Lorazepam & 110 & 0.63 & 5.0 & 0.93 & 22 \\
\hline Diazepam & 2000 & 0.50 & 36 & 0.95 & 56 \\
\hline Flurazepam & 2500 & 0.57 & 58 & 0.83 & 43 \\
\hline CL 218872 & 320 & 0.81 & 200 & 0.72 & 1.6 \\
\hline Ro $15-1788$ & 5 & 0.97 & 5 & 0.89 & 1.0 \\
\hline CGS 8216 & 0.58 & 0.93 & 0.58 & 0.89 & 1.0 \\
\hline CGS 9896 & 3.6 & 1.2 & 3.6 & 1.1 & 1.0 \\
\hline $\begin{array}{l}\text { Ethyl- } \beta \text {-carboline-3- } \\
\text { carboxylate }\end{array}$ & 17 & 1.1 & 8 & 1.2 & 2.1 \\
\hline $\begin{array}{l}\text { Methyl- } \beta \text {-carboline- } 3 \text { - } \\
\text { carboxylate }\end{array}$ & 8 & 1.1 & 10 & 0.88 & 0.8 \\
\hline$\Lambda$ cyl- $\beta$-carboline & 35 & 0.99 & 32 & 0.90 & 1.1 \\
\hline
\end{tabular}

$"$ Ratio $=\mathrm{IC}_{50}$ (photolabeled tissue) $/ \mathrm{IC}_{50}$ (control tissue). technical reasons, are limited in the range of ligand concentrations tested, such low affinity states for benzodiazepine binding would not be measured. Thus, an apparent loss in the number of flunitrazepam binding sites would occur. Attempts to measure these low affinity sites by direct binding studies were not undertaken because of the necessity of using extraordinarily high concentrations of radiolabeled benzodiazepine of high enough specific activity to detect a low affinity, low capacity site. The only report directly measuring possible low affinity benzodiazepine binding sites finds such sites to be of much greater capacity (Bowling and DeLorenzo, 1982) and with rather different pharmacological properties. The low sites studied in this paper are also not identical to the "peripheral type" sites since $\beta$-carboline esters, Ro 15-1788, and CGS-8216 do not bind to kidney membranes in a specific manner, and the compound Ro 5-4864 does not

\section{TABLE III}

$I C_{50}$ and Hill coefficients for inhibition of [3H]-CGS 8216 binding

Control and photolabeled forebrain tissue was prepared as described in Table I (also see "Materials and Methods"). Displacement curves for each inhibitor were determined as shown in Figure 4 for diazepam. The ligand concentration was $0.4 \mathrm{~nm}$. The Hill coefficient, $n_{\mathrm{H}}$, was determined as described in Table II.

\begin{tabular}{|c|c|c|c|c|c|}
\hline \multirow{2}{*}{ Inhibitor } & \multicolumn{2}{|c|}{$\begin{array}{l}\text { Photolabeled } \\
\text { Membranes }\end{array}$} & \multicolumn{2}{|c|}{$\begin{array}{c}\text { Control } \\
\text { Membranes }\end{array}$} & \multirow{2}{*}{ Ratio $^{*}$} \\
\hline & $\mathrm{IC}_{5,0}$ & $n_{\mathrm{H}}$ & $\mathrm{IC}_{50}$ & $n_{\mathrm{H}}$ & \\
\hline & $n M$ & & $n M$ & & \\
\hline Diazepam & 2600 & 0.62 & 70 & 0.84 & 37 \\
\hline Flunitrazepam & 290 & 0.60 & 28 & 0.70 & 10 \\
\hline Clonazepam & 100 & 0.67 & 7 & 0.86 & 14 \\
\hline Ro $15-1788$ & 15 & 1.0 & 15 & 1.1 & 1.0 \\
\hline CSG 8216 & 0.63 & 1.1 & 0.50 & 1.1 & 1.3 \\
\hline CGS 9896 & 1.0 & 1.1 & 1.0 & 0.91 & 1.0 \\
\hline Ethyl- $\beta$-carboline- $3-$ & 8 & 0.92 & 8 & 0.88 & 1.0 \\
\hline
\end{tabular}
carboxylate

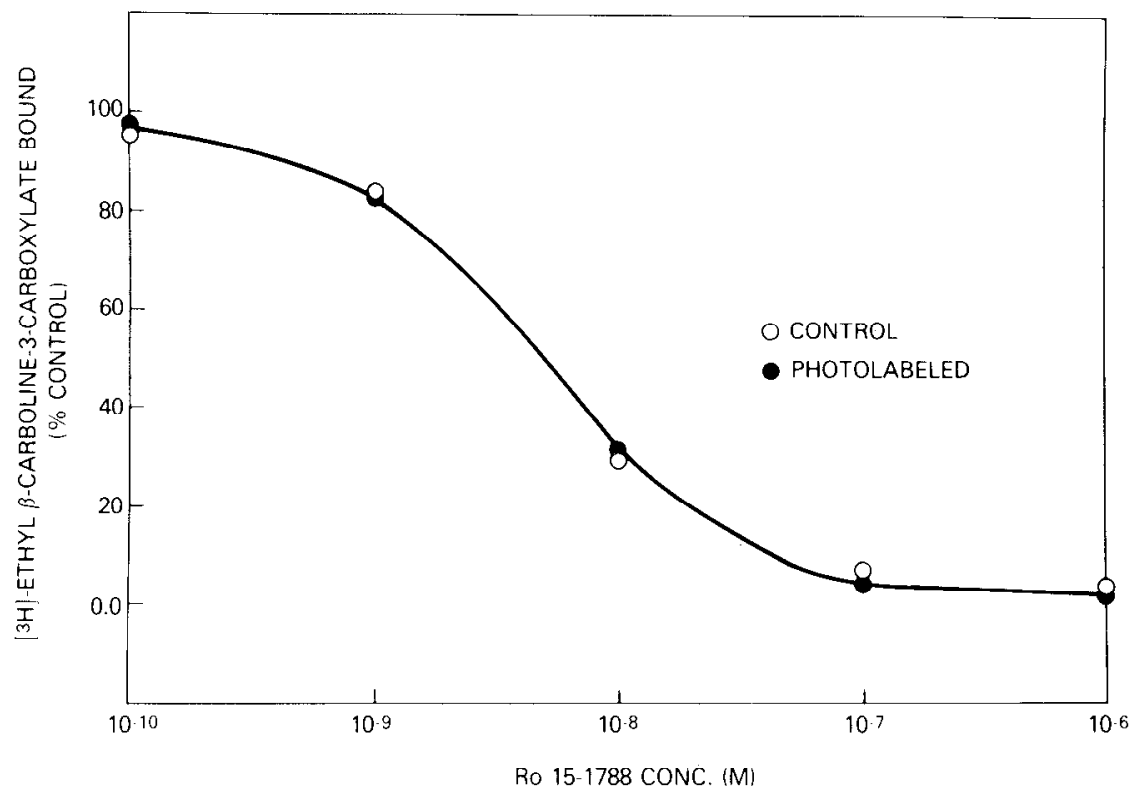

Figure 3. Ro 15-1788 displacement curves of $\left[{ }^{3} \mathrm{H}\right] \beta$-carboline bound to control or photolabeled forebrain tissue. The ligand concentration was 1 nM. 


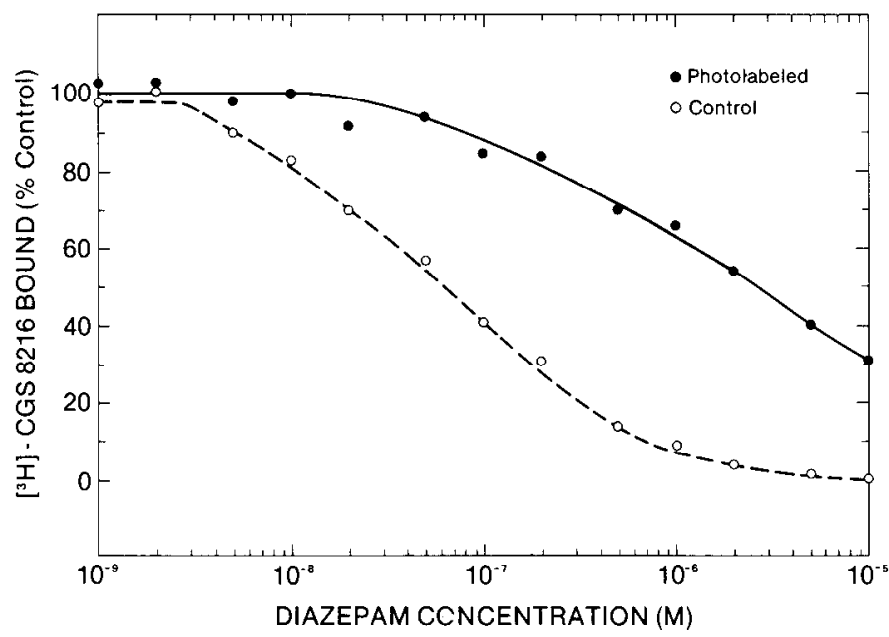

Figure 4. Diazepam displacement curves of $\left[{ }^{3} \mathrm{H}\right] \mathrm{CGS} 8216$ bound to control or photolabeled forebrain tissue. The ligand concentration was $0.4 \mathrm{nM}$.

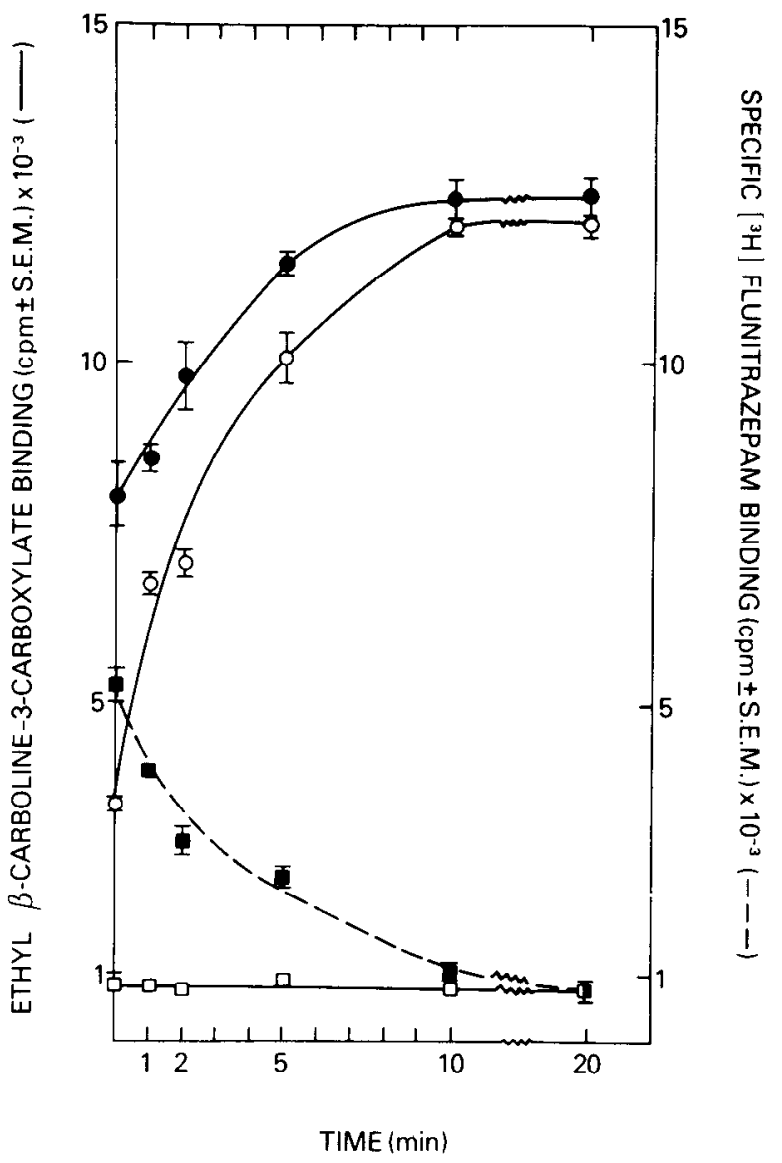

Figure 5. Time course of flunitrazepam photolabeling. Forebrain membranes were prepared, irradiated with ultraviolet light for various lengths of time in the presence of $5 \mathrm{nM}$ flunitrazepam, and washed extensively. The photolabeled membranes were analyzed for $\left[{ }^{3} \mathrm{H}\right]$ ethyl- $\beta$-carboline-3-carboxylate binding (-) and $\left[{ }^{3} \mathrm{H}\right]$ flunitrazepam binding $(---)$. Specific $\left[{ }^{3} \mathrm{H}\right]$ flunitrazepam binding ( $\mathrm{G}$ ) was defined as total binding minus the binding obtained in the presence of $10^{-5} \mathrm{M}$ diazepam. The ligand concentration was $1 \mathrm{~nm}$. For $\left[{ }^{3} \mathrm{H}\right]$ ethyl- $\beta$-carboline-3carboxylate binding, the total binding (O), binding obtained in the presence of $10^{-7} \mathrm{M}$ diazepam $(\mathrm{O})$, and binding obtained in the presence of $10^{-3} \mathrm{M}$ lorazepam $(\square)$ have each been plotted. The $\beta$-carboline ligand was used at a concentration of $1 \mathrm{nM}$. displace binding of any of the labeled antagonists in a range comparable to the centrally active benzodiazepines which all potently displace antagonist binding (Thomas and Tallman, unpublished). We have also indicated elsewhere that peripheral sites are not photolabeled (Thomas and Tallman, 1981).

Instead, since the binding of several antagonists was not significantly altered by photolabeling $(<10 \%)$ and, under basal conditions, is potently displaced by benzodiazepines, the ability of a number of benzodiazepines to displace binding of these antagonists was studied. Under the conditions described here, the ability of benzodiazepines to displace antagonist binding was universally shifted to the right and the displacement curves were flattened (Hill coefficients $<1$ ), consistent with interaction with more than one site. The Hill coefficients less than one obtained for CGS 8216 binding to control membranes may be related to the mixed type of inhibition reported previously by Czernik et al. (1982). This also is consistent with the ability of CGS 8216 , but not Ro 15 1788 , to block pentobarbital's behavioral effects (P. Skolnick, personal communication).

The binding site for the antagonists does not seem to be altered by photolabeling (as measured by direct binding assay or displacement). Similarly, Hirsch et al. (1982) have indicated that that propyl- $\beta$-carboline ester binding was relatively unaffected by photolabeling; in contrast, Möhler (1982) has found that Ro 15-1788 binding was decreased by photolabeling. In our preparation, little decrease has been found with any of the three chemically diverse ligands studied; in no case was it statistically significant or at all close to $25 \%$ (which is the number of sites labeled). The antagonist binding site is, therefore, not identical to the site which is photolabeled by flunitrazepam. Additionally, from displacement studies with reversibly inhibiting benzodiazepines, we can surmise that the site to which the antagonists bind is closely related to the benzodiazepine binding site, but additional constraints on binding of benzodiazepines exist. It is reasonable to hypothesize that the $\beta$-carboline and benzodiazepine sites overlap in some but not all of their steric requirements for binding and that the site which is photolabeled may be separate from both of the reversible binding sites. On the other hand, each photolabeled site seems to be quite intimately related to more than one benzodiazepine site (more sites inactivated than labeled) and can affect binding to these sites in a complicated fashion (perhaps due to site-to-site interactions).

The data presented here are consistent with current thinking about interactions of "agonists" (benzodiazepine-like) and "antagonists" (benzodiazepine-against) with the binding site. The binding of "agonists" is enhanced by allosteric interactions with the GABA receptor (Tallman et al., 1980), whereas binding of the antagonists, methyl-, ethyl-, and propyl- $\beta$-carboline-3-carboxylate, is much less enhanced and in some cases inhibited by GABA (Braestrup et al., 1982). An imidazodiazepine Ro 15-1788, the so-called "selective benzodiazepine antagonist" (Hunkeler et al., 1981; Möhler and Richards, 1981), in our experimental paradigm behaves as a $\beta$-carboline, and its binding, similar to the $\beta$-carbolines, is not altered by GABA. Similarly, a third putative antagonist, CGS8216 , is not altered either by photolabeling or GABA 
(Czernik et al., 1982); again, the displacement by benzodiazepines is shifted to the right while the antagonists are not shifted. It is not yet known whether the alteration in binding by photolabeling and GABA will continue to be correlated.

An interesting observation was made with CL 218,872 (Lippa et al., 1979). This compound has been proposed to distinguish between receptor subtypes on the basis of Hill coefficients $<1$ and by its apparent ability to block photolabeling of one of the forms of benzodiazepine binding site (Sieghart and Karobath, 1980). In our paradigm it does not behave identically to the benzodiazcpines and, therefore, may possess novel pharmacological effects. The binding of the radioactive analog of this compound is altered by GABA, and this provides further insight into the nature of its interaction with the binding site (Niehoff et al., 1982). A compound with similar reported behavioral properties is CGS-9896 (Yokoyama et al., 1982), and other members of this class may be quite interesting potential anxiolytics (for simplicity's sake, they might be classified as partial agonists or antagonists). However, they do not seem to be efficiently distinguished from antagonists in our paradigm; GABA enhances their binding; however, a small GABA effect has also been noted for propyl- $\beta$-carboline ester, an antagonist (Hirsch et al., 1982).

A more far-reaching implication of this study is the ability under some circumstances to convert high affinity to lower affinity benzodiazepine sites. Several studies have indicated that "cryptic" benzodiazepine binding sites are present in brain and that by either physiological stress (Paul and Skolnick, 1978) or pharmacological manipulation in vivo (Gallager et al., 1980) and in vitro (Skolnick et al., 1980) these sites are exposed. Although the low affinity sites seen in the present study were created by an irreversible process which does not occur under physiological conditions, it is possible that the low affinity sites described here may be related to the "cryptic" sites described and that the low affinity state is of functional importance. Experiments to examine this possibility are underway.

Finally, the ability to alter the proportion of high affinity and low affinity benzodiazepine sites separately from $\beta$-carboline sites may be related to heterogeneity described for the benzodiazepine binding site. It is possible that there may be regional or species differences in these high and low affinity sites, and this can be studied by displacement studies of $\beta$-carboline binding following regional photolabeling. It is also possible that heterogenity in the GABA receptor/benzodiazepine binding site/ ionophore complex or occupancy of one or more components with endogenous ligands or drugs may affect the ease of these conformational transitions.

\section{References}

Bowling, A. C., and R. J. DeLorenzo (1982) Micromolar affinity benzodiazepine receptors: Identification and characterization in central nervous system. Science $216: 1247-1249$.

Braestrup, C., and M. Nielsen (1981) GABA reduces binding of $\left[{ }^{3} \mathrm{H}\right]$ methyl $\beta$-carboline-3-carboxylate to brain benzodiazepine receptors. Nature 294: 472-474.

Braestrup, C., R. Schmiechen, G. Neef, M. Nielsen, and E. N. Petersen (1982) Interaction of convulsive ligands with benzodiazepine receptors. Science 216: 1241-1243.
Browner, M., J. W. Ferkany, and S. J. Enna (1981) Biochemical identification of pharmacologically and functionally distinct GABA receptors in rat brain. J. Neurosci. 1: 514-518.

Bylund, D. B. (1980) Analysis of receptor binding data. In Receptor Binding Techniques, pp. 70-99, Society for Neuroscience, Bethesda, MD.

Costa, E., and A. Guidotti (1979) Molecular mechanisms in the receptor action of benzodiazepines. Annu. Rev. Pharmacol. Toxicol. 19: 531-545.

Czernik, A. J., B. Petrack, H. J. Kalinsky, S. Psychoyos, W. D. Cash, C. 'Tsai, R. K. Rinehart, F. R. Granat, R. A. Lovell, D. E. Brundish, and R. Wade (1982) CGS 8216: Receptor binding characteristics of a potent benzodiazepine antagonist. Life Sci. 30: 363-372.

Gallager, D. W., P. Mallorga, and J. F. Tallman (1980) Interaction of diphenylhydantoin and benzodiazepines in the CNS. Brain Res. 189: 209-220.

Gavish, M., R. S. L. Chang, and S. H. Snyder (1979) Solubilization of histamine $\mathrm{H}-1, \mathrm{GABA}$, and benzodiazepine receptors. Life Sci. 25: 783-790.

Glowinski, J., and L. L. Iversen (1966) Regional studies of catecholamines in the rat brain. I. The disposition of $\left[{ }^{3} \mathrm{H}\right]$ norepinephrine, $\left.\Gamma^{3} \mathrm{H}\right]$ dopamine, and $\left.{ }^{3} \mathrm{H}\right\rceil D O P A$ in various regions of the brain. J. Neurochem. 13: 655-669.

Haefely, W., L. Pieri, P. Polc, and R. Schaffner (1981) General pharmacology and neuropharmacology of benzodiazepine derivatives. In Handbook of Experimental Pharmacology, vol. 55/II, F. Hoffmeister and G. Stille, eds., pp. 13-262, SpringerVerlag, Berlin.

Hirsch, J. D., R. L. Kochman, and P. R. Sumner (1982) Heterogeneity of brain benzodiazepine receptors demonstrated by $\left[{ }^{3} \mathrm{H}\right]$ propyl $\beta$-carboline-3-carboxylate binding. Mol. Pharmacol. 21: 618-628.

Hunkeler, W., H. Mohler, L. Pieri, P. Polc, E. P. Bonetti, R. Cumin, R. Schaffner, and W. Haefely (1981) Selective antagonists of benzodiazepines. Nature 290: 514-516.

Lang, B., E. A. Barnard, L.-R. Chang, and J. O. Dolly (1979) Putative benzodiazepine receptor: A protein solubilized from brain. FEBS Lett. 104: 149-153.

Leeb-Lundberg, F., and R. W. Olsen (1980) Picrotoxinin binding as a probe of the GABA postsynaptic membrane receptorionophore complex. In Psychopharmacology and Biochemistry of Neurotransmitter Receptors, H. I. Yamamura, R. W. Olsen, and E. Usdin, eds., pp. 551-568, Elsevier/North Holland, New York.

Lippa, A. S., J. Coupet, E. N. Greenblatt, C. A. Klepner, and B. Beer (1979) A synthetic non-benzodiazepine ligand for benzodiazepine receptors: A probe for investigating neuronal substrates of anxiety. Pharmacol. Biochem. Behav. 11: 99 106.

Massotti, M., A. Guidotti, and E. Costa (1981) Characterization of benzodiazepine and gamma-aminobutyric recognition sites and their endogenous modulators. J. Neurosci. 1: 409-418.

Möhler, H. (1982) Benzodiazepine receptors: Differential interaction of benzodiazepine agonists and antagonists after photoaffinity labeling with flunitrazepam. Eur. J. Pharmacol. 80: 435-436.

Möhler, H., and J. G. Richards (1981) Agonist and antagonist benzodiazepine receptor interaction in vitro. Nature 294: $763-765$.

Möhler, H., M. K. Battersby, and J. G. Richards (1980) Benzodiazepine receptor protein identified and visualized in brain tissue by a photo affinity label. Proc. Natl. Acad. Sci. U. S. A. $77: 1666-1670$.

Niehoff, D., R. D. Mashal, W. D. Horst, R. A. O'Brien, J. M. Palacios, and M. Kuhar (1982) The binding of a radiolabeled triazolopyridazine to a subtype of benzodiazepine receptor in the rat cerebellum. J. Pharmacol. Exp. Ther., 221: 670-675.

Nielsen, M., H. Schou, and C. Braestrup (1981) [ $\left.{ }^{3} \mathrm{H}\right]$-Propyl- $\beta$ - 
carboline-3-carboxylate binds specifically to brain benzodiazepine receptors. J. Neurochem. 36: 276-285.

Paul, S. M., and P. Skolnick (1978) Rapid changes in brain benzodiazepine receptors after experimental seizures. Science 202: 892-894.

Sieghart, W., and M. Karobath (1980) Molecular heterogeneity of benzodiazepine receptors. Nature 286: 285-287.

Skolnick, P., K-L. Lock, B. Paugh, P. Marangos, R. Windsor, and S. Paul (1980) Pharmacologic and behavioral effects of EMD 28422: A novel purine which enhances $\left[{ }^{3} \mathrm{H}\right]$-diazepam binding to brain benzodiazepine receptors. Pharmacol. Biochem. Behav. 12: 685-689.

Tallman, J. F., J. W. Thomas, and D. W. Gallager (1978) GABAergic modulation of benzodiazepine binding site sensitivity. Nature 274: 384-385.

Tallman, J. F., S. M. Paul, P. Skolnick, and D. W. Gallager
(1980) Receptors for the age of anxiety: Pharmacology of the benzodiazepines. Science 207: 274-281.

Thomas, J. W., and J. F. Tallman (1981) Characterization of photoaffinity labeling of benzodiazepine binding sites. J. Biol. Chem. 256: 9838-9842.

Williams, M., and E. A. Risley (1979) Enhancement of binding of ${ }^{3} \mathrm{H}$-diazepam to rat brain membranes in vitro by $\mathrm{SQ} 20,009$, a novel anxiolytic, gamma-aminobutyric acid (GABA) and muscimol. Life Sci. 24: 833-842.

Yokoyama, N., B. Ritter, and A. D. Neubert (1982) 2-Arylpyrazolo[4,3-c]quinolin-3-ones: Novel agonist, partial agonist, and antagonist of benzodiazepines. J. Med. Chem. 25: 337339.

Yousufi, M. A. K., J. W. Thomas, and J. F. Tallman (1979) Solubilization of benzodiazepine binding site from rat cortex. Life Sci. 25: 463-470. 